\title{
Suporte familiar e autoconceito infantojuvenil em acolhidos, escolares e infratores
}

\author{
Family support and self concept in sheltered, students and juvenile offenders
}

\author{
Makilim Nunes Baptista ${ }^{\mathrm{I}}$ \\ Fabián Javier Marin Rueda ${ }^{\text {II }}$ \\ Edna Maria Brandão ${ }^{\text {III }}$
}

\begin{abstract}
Resumo
Este estudo objetivou verificar a percepçáo do suporte familiar e o autoconceito e buscar correlaçóes entre os construtos em três grupos distintos. Participaram 157 crianças e adolescentes de 10 a 18 anos, sendo 68 acolhidos institucionalmente (G1), 58 alunos de escolas públicas (G2) e 31 adolescentes infratores (G3). Foram aplicados o Inventário de Percepção do Suporte Familiar (IPSF) e a Escala de Autoconceito Infantojuvenil (EAC-IJ). Os principais resultados mostraram que os grupos G1, G2 e G3 se mantiveram em ordem crescente quanto às médias apresentadas, tanto em suporte familiar quanto em autoconceito. Foram encontradas correlaçôes de magnitudes fracas ou moderadas entre os instrumentos. Aúnica correlação que se manteve, nos três grupos, foi entre o Autoconceito Familiar e o Fator Afetivo Consistente. Os resultados obtidos corroboraram com a literatura no sentido de associar o suporte familiar ao desenvolvimento do autoconceito. Futuras pesquisas podem investigar estes dois construtos em diferentes grupos de crianças e adolescentes.
\end{abstract}

Palavras chave: Família; Autoconceito; Crianças; Adolescência.

\section{Abstract}

This study aimed to verify the perception of family support and self-concept and seek correlations between the constructs in three different groups. Participants 157 children and adolescents aged between 10 and 18 years and 68 received institutionally (G1), 58 public school students (G2) and 31 adolescents offenders (G3). Inventário de Percepção do Suporte Familiar (IPSF) and the Escala de Autoconceito Infantojuvenil (EAC-IJ) were applied. The main results showed that the groups G1, G2 and G3 remained in ascending order as the averages presented, both in family support as in self-concept. Weak or moderate correlations were found between instruments. The only correlation that remained was between the Family Selfconcept and Affective Factor Consistent. The results corroborate the literature for inclusion of family support development of self-concept. Future research can investigate these two constructs in different groups of children and adolescents

Keywords: Family; Self-concept; Children; Teens.

${ }^{\mathrm{I}}$ Docente do Programa de Pós - Graduação Stricto Sensu em Psicologia da Universidade São Francisco (USF), Itatiba-SP

${ }^{\text {II } D o c e n t e ~ d o ~ P r o g r a m a ~ d e ~ P o ́ s ~-~ G r a d u a c ̧ a ̃ o ~ S t r i c t o ~ S e n s u ~ e m ~ P s i c o l o g i a ~ d a ~ U n i v e r s i d a d e ~ S a ́ o ~ F r a n c i s c o ~(U S F), ~ I t a t i b a-S P ~}$

III Doutoranda em Psicologia no Programa de Pós - Graduação Stricto Sensu em Psicologia da Universidade Sáo Francisco (USF), Itatiba-SP

Diferentes fatores atuam diretamente na avaliação que o indivíduo faz de si mesmo, no entanto, podem ser destacadas as relaçóes que se estabelecem no grupo familiar do qual o indivíduo faz parte como um fator preponderante (Nogueira \& Nogueira, 2002). O ambiente, com seus suportes sociais, entre eles o suporte familiar, exerce influência direta no desenvolvimento da personalidade, o que inclui a percepção de si próprio, ou seja, o autoconceito. $\mathrm{O}$ autoconceito se apresenta como um produto de interaçóes biológicas, sociais e psicológicas, com fundamental importância e papel de destaque para as relaçóes estabelecidas na família (Arpini \& Quintana, 2003).

A família é considerada um modelo de suporte econômico, afetivo e social para seus membros, por meio do qual facilita o desenvolvimento biopsicoemocional (Dessen, 2010). Neste sentido, o suporte familiar pode ser definido como a quantidade de cuidado e proteçâo que os filhos recebem dos pais, assim como a que o grupo familiar proporciona aos integrantes da família como um todo, incluindo incentivo à autonomia, afeto, cooperação, sensibilidade e aceitação, dentre outras características importantes ao desenvolvimento (Baptista, 2009).

Há consenso na literatura sobre o fato de que a percepção de um suporte familiar como adequado constitui um fator protetivo aos aspectos ligados aos transtornos afetivos em crianças, adolescentes e adultos (Gonçalves, Baptista e Farcas, 2016). A proporção em que o suporte familiar é ou deixa de ser fornecido, pode ter relação direta ao modo como a pessoa se auto avalia, bem como avalia as informaçóes vindas do meio em que está inserido (Baptista, Baptista\& Dias 2001).O suporte fornecido e recebido pela família, por meio dos padrôes de relacionamento e comunicação entre seus membros, pode ser considerado um amortecedor dos efeitos de estressores e tende a favorecer a competência social, estratégias de enfrentamento das dificuldades da vida, senso de estabilidade, afeto positivo, bem estar psicológico e o autoconceito positivo (Rigotto, 2006; Santos, 2006). 
Ainda no que diz respeito à construção do autoconceito positivo, Cunha, Sisto e Machado (2007) observaram que a interação entre os integrantes da família pode proporcionar à criança a percepção do que se espera dela. Tendo em vista que a construção de vínculos emocionais no grupo familiar pode ser harmoniosa e solidária ou carregada de raiva e ressentimento, a família coesa e afetuosa parece possuir um papel de fundamental importância no desenvolvimento saudável do autoconceito. Adicionalmente, para Peixoto (2004), o autoconceito resulta de diversos fatores, entre eles e com destacada importância, a qualidade do funcionamento familiar, ou seja, um bom relacionamento entre os integrantes da família pode possibilitar o desenvolvimento de sentimentos de competência e de valores positivos.

Uma definição bastante aceita de autoconceito foi expressa por Shavelson, Hubner e Stanton (1976), que o definiram como a percepção que o indivíduo tem de si mesmo, sendo quea percepçáo seria formada pela experiência com o ambiente do qual a pessoa faz parte e pelas pessoas significativas em sua vida. Acrescentaram que esta percepção influencia suas ações e estas, por sua vez, tem influencia em como a pessoa e os outros a percebem.Chapman (1988) compartilha da mesma ideia e descreve o autoconceito como um conjunto de crenças e autopercepçóes construídas ao longo da vida, que envolve a avaliação cognitiva sobre capacidade, habilidade e aceitação social, que o individuo faz de si mesmo e direcionam a sua conduta perante a vida.

No mesmo sentido Sisto e Martinelli (2004) afirmam que o autoconceito começa a ser construído nas fases iniciais do desenvolvimento humano, se constrói com o passar do tempo, ao longo de cada etapa da vida, influenciado por fatores positivos ou negativos, decorrentes das vivências em diferentes contextos da vida, como a família, escola, grupo de pares, entre outros. As crianças recebem informaçóes sobre si mesmas dos adultos significativos em sua vida e das impressóes recebidas desenvolvem uma imagem positiva ou negativa de si mesmas. O indivíduo que possui figuras parentais emocionalmente adequadas e que lhe dão suporte tenderá a construir um modelo de $e u$ adequado e carregado de valores e virtudes. Contudo, aquele que vivencia rejeição, poderá formar um modelo de eu desvalorizado.

Como se pode perceber a literatura indica que parece haver associação entre suporte familiar oferecido e/ou percebido de modo adequado e o desenvolvimento sadio dos membros da família, o que inclui um autoconceito positivo. Neste sentido, serão apresentadas a seguir em ordem cronológica, algumas pesquisas, nacionais e internacionais, que investigaram o suporte familiar e o autoconceito entre si ou relacionados a diferentes construtos.

Em um trabalho desenvolvido com 287 crianças com idades variando entre 11 e 14 anos, sendo 144 meninas e 143 meninos de uma escola pública, Saric, Rijavec e Zganec (2001) abordaram as práticas parentais tais como afetividade, consistência, disciplina sem práticas punitivas, as quais estariam associadas com um desenvolvimento sadio dos indivíduos. Os resultados indicaram que relaçôes parentais satisfatórias tenderiam a estar associadas a maior autoconceito social e com mais comportamentos considerados saudáveis às normas sociais.

Kim e Ciccetti (2003) estudaram uma amostra com 500 crianças entre 5 e 12 anos, divididas em dois grupos, sendo um de 305 crianças vítimas de maus tratos e 195 crianças não vitimizadas. Os autores identificaram que crianças que perceberam o recebimento de carinho, atenção e afetividade por parte dos pais como deficitário também possuíam uma tendência de se julgarem menos capazes para desempenhar determinadas tarefas e possuíam déficits no desenvolvimento de autonomia. $\mathrm{O}$ estudo indicou a importância das relações familiares, tanto em termos de relaçôes sociais e legais quanto ao desenvolvimento do autoconceito positivo.

Por intermédio de íntima relação entre os construtos, a autoestima reflete um significado afetivo que a pessoa faz de si mesma (Harter, 2003). Assim, com o objetivo de estudara relação entre a interação familiar e a autoestima em adolescentes, Weber, Stasiak e Brandenburg (2003) trabalharam com uma amostra de 111 alunos de escolas particulares, com idades de $13 \mathrm{e}$ 14 anos. Os instrumentos utilizados foram a Escala de Autoestima de Rosenberg e as Escalas de Qualidade de Interação Familiar de Weber, Viezzer e Brandenburg. Os resultados mostraram que perceber um ambiente familiar adequado pode contribuir com o desenvolvimento de melhor autoestima em adolescentes.

Silva (2009) objetivou pesquisar o autoconceito em crianças e pré-adolescentes com e sem história de maus tratos. A amostra foi composta por 90 participantes da cidade do Porto em Portugal, com idades entre 8 e 12 anos, divididas em três grupos, um deles formado por 37 participantes em acolhimento familiar e outro com 25 que moravam em instituiçóes de acolhimento, ambos com histórico de maus-tratos e um terceiro grupo com 28 participantes que viviam com suas famílias de origem e sem histórico de maus tratos. Os instrumentos utilizados foram um questionário sociodemográfico e a Escala de Autoconceito e de Autoestima intitulada "Como é que eu sou", composta por oito 
subescalas e destinada a crianças e pré-adolescentes. $\mathrm{O}$ estudo indicou que o grupo com história de maus tratos pela família, de modo geral, se percebia como menos popular e menos socialmente aceito e as crianças e préadolescentes de famílias nucleares sem histórico de maus tratos possuíam percepção mais positiva de si. Indicou ainda que a história de maus tratos por parte da família pode ser associada a um autoconceito social inferior.

Zape e Dias (2012) realizaram, por meio de estudo de casos múltiplos, pesquisa com cinco adolescentes do sexo masculino, autores de algum ato infracional, com idades entre 15 e 18 anos. Após a análise das informaçóes, os resultados mostraram a ocorrência de haverem sido vítimas de maus tratos por meio da violência doméstica, assim como se evidenciaram fragilidades nas relações familiares e indicadores de dificuldades no processo de construção da própria identidade. Os autores destacaram a falta de suporte por parte dos familiares em uma fase estruturante da vida como é a adolescência e concluíram que há necessidade de investimento em trabalhos com a família, a qual exerce papel essencial no desenvolvimento das crianças e adolescentes, podendo ser vista como fator de risco ou de proteção para o desenvolvimento de seus integrantes.

A partir de uma amostra composta por 343 adolescentes com idades entre 11 e 18 anos, Moscaritolo, Rocha e Silvares (2013) pesquisaram indicadores de autoconceito a partir de autorrelatos sobre aspectos positivos e preocupaçôes. Os autores utilizaram como instrumento único o inventário de autoavaliação para adolescentes, versão brasileira do YouthSelf-Report (YSR). A partir das análises dos resultados obtidos, os autores puderam afirmar que o contexto no qual o jovem está inserido é decisivo para a construçáo de um autoconceito positivo. Também destacaram a necessidade de que principalmente os ambientes domésticos e escolares sejam estimulantes e possam propiciar um desenvolvimento saudável para o indivíduo.

Em síntese, as pesquisas selecionadas trabalharam com crianças e adolescentes escolares, vitimizados e autores de ato infracional, embora não tenha sido encontrado estudo com os três grupos que compuseram a amostra deste trabalho.Saric, Rijavec e Zganec (2001) e Silva (2009) trabalharam com escolares e crianças e adolescentes vitimizados e encontraram o suporte familiar associado ao autoconceito pessoal. Kim e Ciccetti (2003) e Zape e Dias (2012) tiveram como amostras crianças e adolescentes vitimizados e autores de ato infracional e apontaram que perceber um adequado suporte familiar pode contribuir para a formação de um autoconceito pessoal positivo.Nos estudos apresentados foi indicada a associação entre o suporte familiar adequado e o conceito que o indivíduo tem de si mesmo. Esta associação também pode ser encontrada nos estudos de Oliver e Paul (1995), Sanchez e Escribano (1999), Yunes et al (2001), Rigotto (2006), Baptista e Santos (2008) e de Moscaritolo, Rocha e Silvares (2013).Deste modo, objetivou-se no presente estudo verificar a percepção do suporte familiar e o autoconceito em uma amostra brasileira de crianças e adolescentes de três grupos distintos e compará-los, bem como buscar correlaçóes entre os construtos, por meio dos instrumentos utilizados,sob as hipóteses de que os grupos se diferenciem entre si e sejam encontradas as correlaçóes.

\section{Método}

\section{Descrição dos participantes}

Participaram da presente pesquisa 157 crianças e adolescentes de ambos os sexos, estudantes de escolas públicas, com idades entre 10 e 18 anos. A amostra foi composta por três grupos a seguir descritos e denominados G1, G2 e G3.

O G1 foi constituído por 68 crianças e adolescentes acolhidos em instituiçôes localizadas em quatro cidades do interior de São Paulo e uma cidade do sul de Minas Gerais. Do total do grupo 54,4\% eram meninas. As idades variaram entre 10 e 16 anos $(M=13,28$; $\mathrm{DP}=1,66)$ e a escolaridade entre o $3^{\circ}$ e o $9^{\circ}$ ano do ensino fundamental. As crianças e adolescentes estavam acolhidos na instituiçáo pelo período entre 15 dias e 115 meses, sendo que 50\% ( $n=34)$ haviam sido acolhidos há menos de dois anos. Os principais motivos pelos quais as crianças e adolescentes foram afastados de suas famílias de origem foram negligência familiar $(38,2 \% ; n=26)$, uso e abuso de drogas lícitas e ilícitas pelos familiares $(16,3 \% ; n=11)$, suspeita ou confirmação de abuso sexual infantil $(13,3 \% ; n=9)$ e situação de prisão dos pais ou responsáveis $(11,8 \% ; \mathrm{n}=8)$.

O G2 foi formado por 58 alunos de duas escolas públicas de um bairro de periferia de uma cidade do interior paulista. A maioria do grupo (51,7\%) era do sexo masculino, com idades entres 10 e 16 anos $(\mathrm{M}=12,12$ : $\mathrm{DP}=1,27)$.O grupo foi composto por alunos do $5^{\circ}$ e $7^{\circ}$ ano do ensino fundamental. Do total do grupo, 63,8\% vivia com a família nuclear, composta pelo pai, mãe e irmãos, os demais moravam com famílias compostas por padrastos, madrastas, avós, e outros, sem a presença do pai e/ou da mãe residindo com eles.

No G3 participaram 31 adolescentes em conflito com a lei, os quais cumpriam medidas socioeducativas 
de prestação de serviços à comunidade e/ou liberdade assistida, acompanhados por equipe multidisciplinar de uma instituição do interior de São Paulo. No grupo havia $90,3 \%$ de meninos. As idades ficaram entre $14 \mathrm{e}$ 18 anos $(M=16,00 ; D P=1,31)$ e a escolaridade variou entre $04^{\circ}$ ano do ensino fundamental até o $3^{\circ}$ do ensino médio, sendo que quatro participantes $(13 \% ; n=4)$ estavam cursando o Ensino para Jovens e Adultos (EJA) no formato supletivo. Do total do grupo $84 \%$ cumpriam duas medidas socioeducativas e $22,5 \%$ eram reincidentes. Entre os participantes do grupo 16,13\% residia com o pai, mãe e irmãos, o restante vivia com outros familiares, sem que o pai e/ou a mãe morasse com eles.

Os grupos G1 e G2 apresentaram a mesma variação de idade, entre 10 e 16 anos. Com relação ao G3, neste estudo, os adolescentes em conflito com a lei eram mais velhos, porque praticaram o ato já na adolescência ou porque receberam puniçóes mais leves antes de medidas mais restritivas. Todos os participantes eram estudantes de escolas públicas. Contudo, nos grupos $\mathrm{G} 1$ e G3, tendo em vista a variaçáo dos anos escolares que estavam cursando, a idade nem sempre correspondeu a série em que deveriam estar. Este dado pode indicar que condiçóes tais como acolhimento institucional e a situaçáo de conflito com a lei, podem provocar um atraso no cumprimento serial da educação formal. Relatório da Unesco (2012) referente ao Brasil aponta causas como situação de risco, trabalho infantil e renda familiar como fatores que contribuem para o abandono da escola e aumento da taxa de distorção entre a idade e o ano escolar regular.

\section{Instrumentos}

\section{Questionários de identificação}

As questôes em comum abordadas nos questionários para os três grupos foram as iniciais do nome, sexo, idade e ano escolar que estavam cursando. Adicionalmente para o G1 foi perguntado o tempo e o motivo do acolhimento, informaçóes repassadas pela instituição. Para os grupos G2 e G3 foi questionado com quais familiares residiam. Por fim, para o G3 foi perguntado quais medidas socioeducativas estava cumprindo e se era reincidente ou náo em atos infracionais.

Inventário de Percepção do Suporte Familiar (IPSF) - (Baptista, 2009)

O Inventário de Percepção do Suporte Familiar (IPSF) avalia a percepção do indivíduo acerca do suporte que recebe de sua família. $\mathrm{O}$ instrumento é destinado à faixa etária entre 11 e 60 anos de idade. Possui 42 itens que formam uma escala tipo Likert de três pontos, a saber, "sempre ou quase sempre", "às vezes", e "quase nunca ou nunca". O IPSF possui três fatores, sendo o primeiro denominado Afetivo Consistente $(\alpha=0,91)$ que se refere à expressão de afetividade entre os membros da família (verbal e náo verbal), interesse, proximidade, acolhimento, comunicação, interação, respeito, empatia, clareza nas regras intrafamiliares, consistência de comportamentos e verbalizaçóes e habilidade na resolução de problemas. O segundo Fator é o de Adaptação Familiar $(\alpha=0,90)$ referente à ausência de sentimentos e comportamentos negativos em relação à família, tais como raiva, isolamento, incompreensão, relaçóes agressivas (brigas e gritos), além de competitividade entre os familiares. Por fim, o terceiro Fator denominado Autonomia Familiar $(\alpha=0,78)$ refere-se às relaçóes de confiança, liberdade e privacidade entre os membros da família. As dimensóes apresentaram eigenvalues superiores a 2,5 , explicando $41,4 \%$ da variância total e cargas fatoriais acima de 0,30. A normatização do IPSF está dividida em quatro categorias, a saber, "baixo", "médio baixo", "médio alto" e "alto" que medem os níveis de percepção do suporte familiar de acordo com a pontuaçáo do respondente.

\section{Escala de Autoconceito Infanto Juvenil (EAC-IJ)-(Sisto\& Martinelli, 2004)}

A Escala avalia o autoconceito em crianças e adolescentes com idades entre oito e dezesseis anos. A EAC-IJ é composta por 20 itens em formato tipo Likert com as opçôes de resposta "nunca", "às vezes" e "sempre". Possui quatro subescalas, a saber, Pessoal $(\alpha=0,68)$ que avalia os sentimentos que a pessoa tem com relaçáo ao seu modo de ser e agir em diferentes situaçóes, carregado de emoçóes ou lidando bem com elas. Escolar $(\alpha=0,76)$ que trata de questóes relativas às relaçôes interpessoais que ocorrem no contexto escolar, tais como possibilidades de liderança, ser academicamente visto como esperto e ter as suas colocaçôes aceitas pelos colegas e ao mesmo tempo ser reconhecido como uma pessoa bondosa e divertida, tanto no sentido positivo como negativo. A subescala Familiar $(\alpha=0,82)$ se refere ao comportamento adotado nas situaçóes do dia a dia em casa com os pais e irmãos, a saber, ser cuidadoso com as coisas, dizer a verdade e fazer corretamente o solicitado pela família, possibilitando condutas positivas e negativas em relação a eles. Por fim, a dimensão do Autoconceito Social $(\alpha=0,82)$ referente às relaçóes 
sociais com os colegas e como a pessoa se percebe nessas relações, avaliando as capacidades intelectuais, a vontade de ser igual ou melhor que os outros, o desejo de ajudar os amigos e ser ajudado quando necessitar.

\section{Procedimentos}

A pesquisa foi aprovada por Comitê de Ética em Pesquisa com Seres Humanos e autorizada pelas instituições de acolhimento, escola e pela instituição responsável pelo cumprimento das medidas socioeducativas aplicadas aos adolescentes. O Termo de Consentimento Livre e Esclarecido (TCLE), para que as crianças e adolescentes pudessem participar da pesquisa foi assinado, no caso do G1 pelo coordenador da instituição de acolhimento e nos grupos G2 e G3 pelos pais ou responsáveis. Os participantes dos grupos $\mathrm{G} 1$ e $\mathrm{G} 2$ responderam aos instrumentos coletivamente e os do G3 de forma individual, sendo a aplicação da EAC-IJ anterior ao IPSF. Para as análises descritivas e inferenciais foi utilizado o programa estatístico SPSS versão 20.0. As técnicas empregadas foram ANOVA para comparação dos grupos com post hoc de Tukeye nas correlaçóes foi utilizado o coeficiente de Pearson, sempre utilizando o nível de significância de 5\%.

\section{Resultados}

No que diz respeito aos dados sociodemográficos questionados na identificação dos grupos, os resultados demonstraram que em relação ao tempo e aos motivos que levaram ao acolhimento institucional os integrantes do grupo G1, os resultados evidenciados no presente estudo, tanto em termos de tempo de acolhimento como do motivo, corroboraram com a literatura. As motivaçóes negligência ou abandono, drogadiçáo e abuso sexual como os principais motivos do acolhimento institucional e o período de menos de dois anos de permanência na instituição para a maioria dos participantes (São Paulo, 2004; Siqueira et al, 2006; Vitale et al, 2008; Pereira et al, 2010).

Ao G2 foi perguntado com quais familiares residia e a maioria dos integrantes $(63,08 \%)$ respondeu que vivia com a família nuclear composta por pais e irmãos. Por outro lado, no G3 a minoria (16,13\%) tinha a mesma configuração familiar. De forma semelhante, em estudo realizado por Ferruzi (2006) com um grupo de adolescentes em conflito com a lei e outro grupo de alunos de escola pública, dentre estes últimos $62,5 \%$ residia com pai, mãe e irmãos.

Quanto ao nível socioeconômico, a falta de recursos financeiros ou dificuldades de acesso aos recursos sociais necessários, como habitação, saúde, educação, transporte, entre outros, embora não impeça o oferecimento do suporte familiar, não deixa de ser um agente estressor enfrentado pelas famílias e pode afetar o suporte oferecido, bem como a percepção desse suporte pelos integrantes do grupo familiar. Resultados neste sentido podem ser encontradas nos estudos de Venturini et al (2004), Baptista e Santos (2008) e Souza, Baptista e Alves (2008) que indicaram que pessoas com maiores níveis de classe social e econômica percebem maior afetividade e suporte familiar.

Inicialmente serão apresentados os resultados obtidos pelos participantes da amostra em cada um dos instrumentos aplicados. A Tabela 1 mostra a pontuaçáo dos três grupos nos Fatores que compóem o IPSF e nas Dimensôes que formam a EAC-IJ.

\section{Tabela 1}

Pontuação e comparação dos grupos nos Fatores e Total do IPSF e nas

Dimensóes e Geral da EAC-IJ

\begin{tabular}{cccccccc}
\hline & \multicolumn{2}{c}{ G1 } & G2 & \multicolumn{3}{c}{ G3 } & M \\
\cline { 2 - 7 } & M & DP & M & DP & M & DP \\
\hline Afetivo Consistente & 26,47 & 1,28 & 28,19 & 1,28 & 31,45 & 1,56 & 5,09 \\
Adaptaçáo & 17,66 & 0,76 & 20,79 & 0,76 & 22,23 & 0,93 & $14,88^{*}$ \\
Autonomia & 8,28 & 0,49 & 8,45 & 0,49 & 9,10 & 0,60 & 1,43 \\
Total IPSF & 52,41 & 1,89 & 58,09 & 1,89 & 62,13 & 2,29 & $10,10^{*}$ \\
Pessoal & 3,46 & 0,30 & 4,72 & 0,30 & 5,13 & 0,36 & $13,97^{*}$ \\
Escolar & 4,09 & 0,34 & 4,13 & 0,34 & 4,65 & 0,41 & 1,55 \\
Familiar & 5,72 & 0,24 & 6,14 & 0,24 & 6,58 & 0,29 & 4,55 \\
Social & 8,00 & 0,41 & 9,05 & 0,41 & 10,39 & 0,50 & $11,54^{*}$ \\
Geral EAC-IJ & 21,82 & 0,72 & 24,00 & 0,72 & 26,23 & 0,87 & $13,37^{*}$ \\
\hline
\end{tabular}

${ }^{*} \mathrm{p}<0,05$. 
Os resultados que se referem às médias dos participantes nos Fatores e no Total do IPSF mostraram diferenças estatísticas entre os grupos, sendo que o G1 se diferenciou dos demais no Fator Adaptação e no Total do IPSF. O G1 apresentou médias mais baixas em todos os Fatores e no IPSF Total. Por outro lado, o G3 apresentou as maiores médias nos Fatores e no Total do IPSF.

No que diz respeito a EAC-IJ os grupos se diferenciaram estatisticamente, sendo G1 na Dimensão Autoconceito Pessoal e o G3 na Dimensão Autoconceito Social. Os três grupos se diferenciaram no Fator Geral da EAC-IJ. O G1 apresentou médias mais baixas em todas as Dimensóes da Escala em relação aos demais grupos. O G3 obteve maiores médias nas Dimensões da Escala e no Fator Geral.

O grupo G2, tanto no IPSF quanto na EAC-IJ, obteve pontuaçóes que ficaram entre as dos grupos $\mathrm{G} 1$ e G3. Assim, as médias dos três grupos G1, G2 e G3 foram, em ordem crescente, respectivamente, nos dois instrumentos aplicados.

A seguir será apresentada a associação entre os construtos Suporte Familiar e Autoconceito por meio das correlaçóes evidenciadas entre o Inventário de Percepção do Suporte Familiar (IPSF) e a Escala de Autoconceito Infantojuvenil (EAC-IJ). As tabelas 2, 3 e 4 demonstram os resultados por grupo.

\section{Tabela 2}

Correlaçôes entre o IPSF e a EAC-IJ no grupo G1

\begin{tabular}{ccccccc}
\hline & & Pessoal & Escolar & Familiar & Social & Geral \\
\hline \multirow{2}{*}{ Afetivo Consistente } & $r$ & 0,01 & 0,09 & $0,28^{*}$ & 0,07 & 0,19 \\
\multirow{3}{*}{ Adaptaçáo } & $\mathrm{p}$ & 0,933 & 0,430 & 0,021 & 0,585 & 0,113 \\
& $r$ & $0,25^{*}$ & $-0,18$ & 0,06 & 0,22 & 0,16 \\
Autonomia & $\mathrm{p}$ & 0,040 & 0,139 & 0,592 & 0,066 & 0,180 \\
& $\mathrm{r}$ & 0,02 & $-0,07$ & 0,08 & 0,13 & 0,08 \\
Total & $\mathrm{p}$ & 0,824 & 0,536 & 0,487 & 0,279 & 0,500 \\
& $\mathrm{r}$ & 0,12 & $-0,02$ & 0,23 & 0,17 & 0,21 \\
& $\mathrm{p}$ & 0,333 & 0,815 & 0,056 & 0,168 & 0,076 \\
\hline
\end{tabular}

${ }^{*} \mathrm{p}<0,05$

Como pode ser observado na Tabela 2,que diz respeito ao $\mathrm{G} 1$, apenas a Dimensão do Autoconceito Pessoal obteve correlação com o Fator Adaptação e a Dimensão Familiar correlacionou-se com o Fator Afetivo-Consistente. A Tabela 3, a seguir, mostra os resultados das correlaçóes no G2.

Tabela 3

Correlaçóes entre o IPSF e a EAC-IJ no grupo G2

\begin{tabular}{ccccccc}
\hline & & Pessoal & Escolar & Familiar & Social & Geral \\
\hline \multirow{2}{*}{ Afetivo Consistente } & $r$ & $-0,01$ & $0,40^{*}$ & $0,36^{*}$ & 0,16 & $0,36^{*}$ \\
\multirow{3}{*}{ Adaptação } & $\mathrm{p}$ & 0,921 & 0,002 & 0,006 & 0,233 & 0,005 \\
& $r$ & $0,45^{*}$ & 0,02 & 0,57 & $0,57^{*}$ & $0,54^{*}$ \\
Autonomia & $\mathrm{p}$ & 0,001 & 0,852 & 0,670 & 0,001 & 0,001 \\
& $\mathrm{r}$ & $-0,27$ & 0,06 & $-0,12$ & $-0,57$ & $-0,58$ \\
Total & $\mathrm{p}$ & 0,840 & 0,631 & 0,338 & 0,671 & 0,666 \\
& $\mathrm{r}$ & 0,17 & $0,31^{*}$ & 0,24 & $0,33^{*}$ & $0,46^{*}$ \\
& $\mathrm{p}$ & 0,201 & 0,017 & 0,071 & 0,001 & 0,001 \\
\hline
\end{tabular}

${ }^{*} \mathrm{p}<0,05$

O G2 apresentou maior número de correlaçôes entre os instrumentos. As correlaçóes se deram entre a Dimensão Pessoal e o Fator Adaptação. A Dimensão Escolar com os Fatores Afetivo-Consistente e com o Total do IPSF. A Dimensão Familiar com o Fator Afetivo-Consistente. Por fim, a Dimensão Social com o Fator Adaptação e também com o Total do IPSF. O Geral da EAC-IJ obteve correlaçóes com os Fatores Afetivo-Consistente, Adaptação e com o Total do IPSF. Somente o fator Autonomia do IPSF não se correlacionou com nenhuma dimensão da EAC-IJ. 
Tabela 4

Correlaçóes entre o IPSF e a EAC-IJ no grupo G3

\begin{tabular}{ccccccc}
\hline & & Pessoal & Escolar & Familiar & Social & Geral \\
\hline \multirow{2}{*}{ Afetivo Consistente } & $r$ & 0,03 & 0,24 & $0,36^{*}$ & $-0,12$ & 0,23 \\
& $\mathrm{p}$ & 0,853 & 0,179 & 0,043 & 0,509 & 0,214 \\
\multirow{2}{*}{ Adaptação } & $\mathrm{r}$ & 0,33 & 0,16 & $0,40^{*}$ & 0,01 & $0,41^{*}$ \\
& $\mathrm{p}$ & 0,068 & 0,378 & 0,026 & 0,959 & 0,020 \\
Autonomia & $\mathrm{r}$ & $-0,24$ & 0,02 & 0,08 & 0,23 & 0,02 \\
& $\mathrm{p}$ & 0,189 & 0,895 & 0,646 & 0,214 & 0,879 \\
Total & $\mathrm{r}$ & 0,03 & 0,23 & $0,40^{*}$ & 0,01 & 0,29 \\
& $\mathrm{p}$ & 0,869 & 0,212 & 0,024 & 0,996 & 0,111 \\
\hline
\end{tabular}

${ }^{*} \mathrm{p}<0,05$

No G3 a Dimensão Autoconceito Familiar se correlacionou com o Fator Afetivo-Consistente, Adaptação e com o Total do IPSF. O Fator Adaptaçáo do IPSF se correlacionou com o Fator Geral da EAC-IJ. As correlaçôes, considerando o total dos participantes da amostra, serão apresentadas na Tabela 5 .

Tabela 5

Correlaçóes entre o IPSF e a EAC-IJ no total da amostra

\begin{tabular}{ccccccc}
\hline & & Pessoal & Escolar & Familiar & Social & Geral \\
\hline \multirow{2}{*}{ Afetivo-Consistente } & $r$ & 0,09 & $0,18^{*}$ & $0,35^{*}$ & $0,15^{*}$ & $0,32^{*}$ \\
& $\mathrm{p}$ & 0,252 & 0,019 & 0,001 & 0,047 & 0,001 \\
\multirow{2}{*}{ Adaptaçáo } & $r$ & $0,42^{*}$ & $-0,11$ & $0,17^{*}$ & $0,42^{*}$ & $0,42^{*}$ \\
& $\mathrm{p}$ & 0,001 & 0,161 & 0,026 & 0,001 & 0,001 \\
Autonomia & $\mathrm{r}$ & $-0,02$ & $-0,02$ & 0,01 & 0,08 & 0,03 \\
& $\mathrm{p}$ & 0,782 & 0,805 & 0,809 & 0,302 & 0,661 \\
\multirow{2}{*}{ IPSF total } & $r$ & $0,23^{*}$ & 0,07 & $0,31^{*}$ & $0,30^{*}$ & $0,40^{*}$ \\
& $\mathrm{p}$ & 0,003 & 0,371 & 0,001 & 0,001 & 0,001 \\
\hline
\end{tabular}

$\mathrm{p}<0,05$

$\mathrm{Na}$ amostra total, o IPSF e a EAC-IJ apresentaram correlaçóes entre o Fator Afetivo-Consistente e as Dimensóes Escolar, Familiar, Social e Geral. O Fator Adaptação se correlacionou com as Dimensóes Pessoal, Familiar, Social e Geral. O Total do IPSF obteve correlações com as Dimensões Pessoal, Familiar, Social e Geral. Apenas o Fator Autonomia do IPSF não se correlacionou com nenhuma Dimensão da EAC-IJ. Todas as correlaçóes apresentadas foram positivas e de magnitudes fracas ou moderadas (Dancey\&Reidy, 2006).

\section{Discussáo}

O objetivo do presente estudo foi verificar a percepçáo do suporte familiar e o autoconceito em crianças e adolescentes escolares, acolhidos institucionalmente e autores de ato infracional, além de comparar os grupos e verificar as correlaçóes entre os construtos por meio dos instrumentos utilizados. Vale lembrar que não foi encontrado nenhum outro estudo no Brasil, até o momento, que buscasse comparar grupos como os que formaram a presente amostra. A escassez de estudos que avaliem crianças e adolescentes em situação de acolhimento institucional ou que cometeram infraçôes dificulta o estabelecimento de comparativos entre os resultados das pesquisas.

Com relação às respostas dadas aos instrumentos, o G1 foi o grupo que apresentou médias mais baixas em todos os Fatores do IPSF e nas Dimensóes da EAC-IJ. Os integrantes do grupo G1, de forma geral, perceberam o suporte familiar recebido como inadequado e apresentaram menor autoconceito. Tais resultados fazem 
sentido na medida em que os membros do G1 se encontravam afastados do convívio com suas famílias. Ademais, a maioria estava na instituição por haverem sido vítimas de negligência, abandono, violência, etc. Apresentar a percepçáo do suporte familiar como inadequado associado ao autoconceito negativo foram resultados apontados também por Kim Ciccetti (2003), Silva (2009), Saric, Rijavec e Zganec (2001) e Zape e Dias (2012).

Por outro lado, o G3 apresentou maiores médias no IPSF e na EAC-IJ, resultados similares aos encontrados nos estudos de Saricetal (2001) e Weber et al (2003), embora este último tenha estudado autoestima, construto semelhante. Ademais, em termos de autoconceito, os integrantes do grupo G3, composto por adolescentes em conflito com a lei, podem se julgar fortes, popularese líderes, atributos requisitados para uma sociabilidade mais valorizada, como forma de participação em grupos específicos, dados semelhantes podem ser encontrados nas pesquisas feitas por Rodkinetal (2000), Stevenatoet al (2003) e Milani e Loureiro (2009).

Neste trabalho os resultados mostraram que o grupo que obteve as menores e maiores pontuaçóes na medida de percepção do suporte familiar também o fizeram em relação à avaliação do autoconceito. Esta relação também foi pesquisada e pode ser encontrada nos estudos de Oliver e Paul (1995), Sanchez e Escribano (1999), Yunes et al (2001), Rigotto (2006) e Baptista e Santos (2008). A literatura indica, de forma geral, que o indivíduo que possui uma percepção positiva do suporte que recebe de sua família, julga-se também mais positivamente acerca de suas características e capacidades em termos pessoais, familiares, sociais, entre outros.

Ainda que de magnitudes fracas ou moderadas foram encontradas correlações entre os fatores do IPSF, exceto o Fator Autonomia, e as dimensôes da EAC-IJ. Ficou evidenciado neste estudo que a percepçáo do suporte familiar recebido se associou ao conceito que o indivíduo tem de si mesmo. Nesse sentido,também Moscaritolo, Rocha e Silvares (2013) afirmaram que o contexto no qual o jovem está inserido é decisivo para a construção de um autoconceito positivo e destacaram a importância de ambientes domésticos e escolares que possam estimular o desenvolvimento saudável do indivíduo.

Em termos das correlaçôes, o grupo que apresentou maior número entre os instrumentos foi o G2. Pode-se hipotetizar maior variação de contextos familiares vivenciados pelas crianças e adolescentes que o compuseram, por se tratar de um grupo não táo específico como os outros dois, uma vez que o G1 estava afastado da família e no G3 a minoria vivia com pais e irmáos. Por outro lado, os integrantes do G2 viviam, em sua maioria, com os pais e irmãos, tal característica pode ter lhes permitido experienciara percepçáo das dimensôes do suporte familiar, o qual de acordo com a literatura citada e corroborada neste estudo está associado ao desenvolvimento do autoconceito positivo.

O Fator Autonomia do IPSF náo se correlacionou com nenhuma Dimensão nem com o Fator Geral da EAC-IJ nos três grupos e também na amostra total. Não é prudente afirmar que não haja associação entre as noçôes das relaçóes familiares que envolvem confiança, privacidade e liberdade e o autoconceito de modo geral. Pode-se hipotetizar que por se tratar de crianças e adolescentes a percepção deste fator não tenha sido táo acentuada. Trabalhos futuros podem explorar mais esta associação e formular hipóteses acerca dela. Por outro lado, destacou-se a correlação entre a Dimensão do Autoconceito Familiar da EAC-IJ e o Fator Afetivo Consistente do IPSF, a qual se manteve nos três grupos e no total da amostra. Vale lembrar que ambos, a Dimensão do Autoconceito Familiar da EAC-IJ e o Fator Afetivo Consistente do IPSF, avaliam aspectos referentes ao contexto da família. A Dimensão Familiar da EAC-IJ se refere ao comportamento adotado nas situaçôes do dia a dia em casa com os pais e irmãos, a saber, ser cuidadoso com as coisas, dizer a verdade e fazer corretamente o solicitado pela família, possibilitando condutas positivas e negativas em relação a eles. Enquanto que o Fator Afetivo Consistente do IPSF diz respeito à expressão de afetividade entre os membros da família (verbal e não verbal), interesse, proximidade, acolhimento, comunicação, interação, respeito, empatia, clareza nas regras intrafamiliares, consistência de comportamentos e verbalizaçóes e habilidade na resolução de problemas.

Em síntese, as hipóteses elencadas no presente estudo,de que os grupos se diferenciariam e seriam encontradas correlaçóes entre os construtos pesquisados por meio dos instrumentos utilizados, foram parcialmente confirmadas. Dada a importância da família para o indivíduo e a percepção deste, do suporte familiar recebido e sua associaçáo com o desenvolvimento do autoconceito, sugere-se que pesquisas futuras possam investigar diferentes grupos de crianças e adolescentes, uma vez que uma das limitaçóes deste estudo foi o número reduzido de participantes em cada grupo. Mostra-se de fundamental importância trabalhos que possam contribuir para a prevenção e desenvolvimento de estratégias que visem um crescimento biopsicossocial saudável das crianças e adolescentes, em especial, 
daquelas que necessitam ver assegurado seu direito à proteçáo integral, como no caso do acolhimento institucional ou em situaçáo de conflito com a lei.

Por fim, o autoconceito não deve somente ser associado à percepção do suporte familiar, já que outras diversas variáveis estão também relacionadas ao desenvolvimento de auto avaliaçóes. Por exemplo, características da personalidade, bem como variáveis biológicas também podem explicar o desenvolvimento do autoconceito em crianças e adolescentes. Provavelmente por estas outras influências, nem todas as correlaçôes foram encontradas, além do que as magnitudes variaram de fracas a moderadas. Nesse sentido, apesar da dificuldade em se ter acesso à essas amostras, pesquisas envolvendo, por exemplo, modelos de mediaçáo/moderação do autoconceito devem explicar melhor quais variáveis pessoais, sociais e/ou biológicas explicariam melhor o desenvolvimento do autoconceito em amostras com características tão peculiares.

\section{Referências}

Arpini, D. M.,\& Quintana, A. M. (2003). Identidade, família e relaçôes sociais em adolescentes de grupos populares. Estudos de Psicologia, 20(1), 27-36.

Baptista, M. N. (2009). Inventário de Percepção de Suporte Familiar. São Paulo: Vetor.

Baptista, M. N., Baptista, A. S. D.,\& Dias, R. R. (2001). Estrutura e Suporte Familiar como fatores de risco na depressão de adolescentes. Psicologia: Ciência e Profissáo, 21 (2), 52-61.

Baptista, M. N., \& Santos, T. M. M. (2008). Suporte familiar, autoeficácia e lócus de controle: evidências de validade entre os construtos. Psicologia: Ciência e Profissão, 28 (2), 260-271.

Chapman, J. W. (1988). Learning disabled children's self-concepts. ReviewofEducationalResearch, 58, 347-371.

Cunha, A. C., Sisto, F. F., \& Machado, F. (2007). Autoconceito e reconhecimento de palavras em crianças do ensino fundamental. Avaliação Psicológica, 6 (2), 147-156.

Dancey, C. P., \&Reidy, J. (2006). Estatistica sem Matemática para Psicologia: usando SPSS para Windows. PortoAlegre: Artmed.

Dessen, M. A. (2010). Estudando a família em desenvolvimento: desafios conceituais e teóricos. Psicologia: Ciência e Profissão,30, 202-219.

Estatuto da Criança e do Adolescente (1990). Lei no 8.069 de 13 de julho de 1990. Brasília.
Ferruzi, A. H. (2006). DFH e adolescentes em conflito com a lei: evidências de validade. Dissertação de Mestrado. Universidade São Francisco. Itatiba.

Gonçalves, M., Baptista, M. N.,\&Farcas, D. (2016). IPSF: análise da estrutura interna em uma amostra de jovens adultos portugueses. Avaliação Psicológica, 15 (1), 115-123.

Harter, S. (1993). Causesandconsequencesoflow selfesteem in childrenandadolescents. EmBaumeister, R. F.(org.).Self-esteem: the puzzle of low self-regard. New York: Plenum.

Kim, J. \&Ciccetti, D. (2003).Social self-efficacy and behavior problems in maltreated and nonmaltreatedchildren.Journal of Clinical Child and Adolescent Psychology, 32 (1), 106-117.

Milani, R. G. \&Loureiro, S. R. (2009).Crianças em risco psicossocial associado à violência doméstica: o desempenho escolar e o autoconceito como condiçôes de proteção. Estudos de Psicologia, 14 (3), 191-198.

Moscaritolo, A. M. F., Rocha, M. M., Silvares, E. F. M. (2013). Indicadores de autoconceito em adolescentes:autorrelato sobre aspectos positivos e preocupaçóes. Revista Psicologia: Teoria e Prática, 15(3), 134-150.

Nogueira, C. M. M.\& Nogueira, M. A. (2002). A sociologia da Educação de Pierre Bourdieu: limites e contribuiçôes. Revista Educação e Sociedade, 78,15-36.

Oliver, J. M,\& Paul, J. C. (1995). Self-esteem and self-efficacy: perceived parenting and family climate and depression in university students. JournalofClinicalPsychology, 51 (4), 467-481.

Peixoto, F. (2004). Qualidade das relaçôes familiares, autoestima, autoconceito e rendimento acadêmico. Análise psicológica, 1(22), 235-244.

Pereira, M., Soares, I., Dias, P., Silva, J., Marques, S., \& Baptista, J. (2010). Desenvolvimento, Psicopatologia e Apego: Estudo exploratório com crianças institucionalizadas e suas cuidadoras. Psicologia: Reflexão e Crítica, 23 (2), 222-231.

Rigotto, D. M. (2006). Evidência de validade entre suporte familiar, suporte social e autoconceito. Dissertação. Mestrado em Psicologia. Universidade São Francisco. Itatiba.

Rodkin, P. C., Farmer, T. W., Pearl, R., \& Arcker, R. V. (2000). Heterogeneity of popular boys: antisocial and prosocial configurations. DevelopmentalPsychology, 36(1), 14-24.

Sánchez, A. V. \& Escribano, E. A. (1999). Medição do Autoconceito. São Paulo: EDUSC. 
Santos, T. M. M. (2006). Evidência de Validade entre Percepção de Suporte Familiar e Traços de Personalidade. Dissertação. Mestrado em Psicologia. Universidade São Francisco. Itatiba.

São Paulo (2004). Prefeitura Municipal de Sáo Paulo. Secretaria de Assistência Social. Reordenamento dos Abrigos Infanto Juvenis da Cidade de São Paulo: Construção da política interinstitucional de defesa dos direitos de convivência familiar e comunitária das crianças e adolescentes de São Paulo. São Paulo: SAS.

Saric, Z. R., Rijavec, M. \& Zganec, A. B. (2001). The relation of parental practices and self-conceptions to young adolescent problem behaviors and substance use.Nord Journal. Psychiatry, 55 (3), 203-209.

Shavelson, R. J.,Hubner, J.J. \& Stanton, G.C. (1976). Self-concept:Validation of Construct Interpretations. ReviewofEducationalResearch, 46, 407-441.

Silva, B. C. L. (2009). O autoconceito de crianças e préadolescentes com e sem história de maus tratos numa amostra de 90 participantes. Dissertação. Mestrado em Psicologia Universidade Fernando Pessoa. Porto. Portugal. Disponível emhttp://www.bdigital.ufp.pt.

Siqueira, A. C., Betts, M. K. \& Dell'Aglio, D. D. (2006). A rede de apoio social e afetivo de adolescentes institucionalizados no sul do Brasil. Revista Interamericana de Psicologia, 40 (2), 149-158.

Sisto, F. F. \& Martinelli, S. C. (2004). Escala de Autoconceito Infanto Juvenil. São Paulo: Vetor.

Souza, M. S., Baptista, M. N. \& Alves, G. A. S. (2008). Suporte familiar e saúde mental: evidência de validade baseada na relação entre variáveis. Aletheia, 28, 45-59.

Stevenato, I. S., Loureiro, S. L., Linhares, M. B. M. \&Marturano, E. M. (2003).Autoconceito de crianças com dificuldades de aprendizagem e problemas decomportamento.Psicologia em Estudo, 8(1), 67-76. Unesco (2012). Organização das Naçóes Unidas para a Educação, a Ciência e a Cultura. Acesso, permanência, aprendizagem e conclusão da Educação Básica na idade certa - Direito de todas e de cada uma das crianças e dos adolescentes. Disponível em http://www.unesco.org. Vitale, M. A. F., Fávero, E. T.\& Baptista, M. V. (Org.) (2008). Familias de crianças e adolescentes abrigados: quem são, como vivem, o que pensam, o que desejam. São Paulo: Paulus.

Weber L. N. D., Stasiak, G. R. \&Brandenburg, O. J. (2003). Percepção da interação familiar e autoestima de adolescentes, Aletheia, 17 (18), 95-105.

Yunes, M. A. M., Arrieche, M. R. O., Tavares, M. F. A. \& Faria, L. C. (2001). Família vivida e pensada na percepção de crianças em situação de rua. Paidéia, $11(20), 47$.

Zappe, J. G.\& Dias, A. C. G. (2012). Violência e fragilidade nas relaçôes familiares: refletindo sobre a situação de adolescentes em conflito com a lei. Estudos de Psicologia (Natal), 17 (3), 389-395.

\section{Endereço para correspondência:}

Prof. Dr. Makilim Nunes Baptista

Programa de Pós-Graduação Stricto-Sensu em

Psicologia da Universidade São Francisco.

R. Waldemar César da Silveira, 105

Vl. Cura D'Ars (SWIFT).

CEP: 13045-510 - Campinas - São Paulo

Email: makilim01@gmail.com

Recebido em 04/01/2017

Aceito em 05/04/2017 